\title{
Glutamate and GABA Release Are Enhanced by Different Subtypes of Presynaptic Nicotinic Receptors in the Lateral Geniculate Nucleus
}

\author{
Jian-Zhong Guo, Trevor L. Tredway, and Vincent A. Chiappinelli \\ Department of Pharmacology, The George Washington University, School of Medicine and Health Sciences, \\ Washington, D.C. 20037
}

The functional role of nicotinic acetylcholine receptors (nAChRs) in the ventral lateral geniculate nucleus (LGNv) was examined in chick brain slices. Whole-cell patch-clamp recordings of neurons in the LGNv revealed the presence of bicuculline-resistant spontaneous postsynaptic currents (PSCs), which were subsequently blocked by 6-cyano-7nitroquinoxaline-2,3-dione (CNQX), an AMPA receptor antagonist. Carbachol and other nicotinic agonists produced marked increases in the frequency of the glutamatergic spontaneous PSCs in the presence of tetrodotoxin, whereas they had little or no effect on current amplitude. The nicotinic receptor antagonist dihydro- $\beta$-erythroidine $(\mathrm{DH} \beta \mathrm{E})$ blocked the carbacholinduced enhancement of spontaneous glutamatergic PSCs. $\alpha$-bungarotoxin ( $\alpha$-BgTx) selectively blocked the nAChRmediated enhancement of spontaneous glutamatergic PSCs

An important function of neuronal nicotinic acetylcholine receptors (nAChRs) in the CNS appears to be modulation of neurotransmitter release (Wonnacott et al., 1990; Vidal and Changeux, 1996; Wonnacott, 1997). Presynaptic nAChRs have been implicated in the enhanced release of a number of transmitters, including norepinephrine, dopamine, serotonin, acetylcholine, GABA, and glutamate (for review, see Role and Berg, 1996). These studies have focused predominantly on nAChR modulation of a single transmitter in a diverse group of synaptosomal and brain slice preparations.

The presynaptic nAChR subtypes, their location, and their mechanisms for enhancing transmitter release vary with each experimental model. Evidence indicates that both $\alpha$-bungarotoxin ( $\alpha$-BgTx) binding nAChRs and high-affinity nicotine binding nAChRs have the ability to modulate transmitter release. In addition, sensitivity to blockade by TTX suggests various locations for these presynaptic nAChRs (Lena et al., 1993). Consequently, it becomes difficult to uniformly define the nature and function of presynaptic nAChRs.

The chick ventral lateral geniculate nucleus (LGNv) is a large retinorecipient region that has a high density of nAChRs (Ehrlich and Mark, 1984; Morris et al., 1990; Sorenson and Chiappinelli,

Received Oct. 24, 1997; revised Dec. 29, 1997; accepted Dec. 31, 1997.

This work was supported by National Institutes of Health Grants NS17574 and NS33135 to V.A.C. The software program KyPlot Version 1.0 that was used to make the figures in this paper was a gift from Dr. K. Yoshioka, Tokyo Medical and Dental University, Tokyo, Japan.

Correspondence should be addressed to Dr. Jian-Zhong Guo, Department of Pharmacology, The George Washington University, School of Medicine and Health Sciences, 2300 Eye Street, N.W., Washington, D.C. 20037.

Copyright (C) 1998 Society for Neuroscience $0270-6474 / 98 / 181963-07 \$ 05.00 / 0$ but did not prevent nAChR-mediated enhancement of spontaneous GABAergic PSCs in the LGNv. Methyllycaconitine and strychnine, other blockers of nAChRs containing the $\alpha 7$ subunit, failed to inhibit carbachol's increase of spontaneous glutamatergic and GABAergic PSCs. These results demonstrate that the LGNv neurons receive both glutamatergic and GABAergic inputs and that the release of these transmitters can be modulated by different presynaptic nAChRs. Thus, the regulation of synaptic efficacy in the brain by presynaptic nAChRs can be complex, involving multiple neurotransmitters acting on the same neuron.

Key words: neuronal nicotinic acetylcholine receptors; presynaptic; glutamate; GABA; modulation; $\alpha$-bungarotoxin; methyllycaconitine; ventral lateral geniculate nucleus
1992). Information that a majority of these receptors are presynaptic comes from a study in which nicotinic agonists caused a marked increase in spontaneous GABAergic postsynaptic currents (PSCs), whereas they produced no significant direct postsynaptic response (McMahon et al., 1994b). GABA release was enhanced even when axonal sodium channels were blocked by tetrodotoxin (TTX), indicating that the nAChRs that were responsible were likely to be located near transmitter release sites on GABAergic nerve terminals. During our studies in the LGNv, we observed spontaneous postsynaptic currents in neurons that were not blocked by the $\mathrm{GABA}_{\mathrm{A}}$-receptor antagonist bicuculline, suggesting that other transmitters were being released. Therefore, the LGNv presented us with the possibility to study concurrent presynaptic $\mathrm{nAChR}$ actions on multiple transmitters in one region.

The goal of the present study was to identify the other transmitters released in the LGNv, determine whether they too are subject to modulation by nAChRs, and further characterize any nAChR-mediated enhancement. We now report that nAChRs located on presynaptic nerve terminals in the LGNv enhance the release of glutamate. The pharmacological properties of the nAChRs enhancing glutamate release are uniquely distinguishable from those responsible for GABA release, indicating different receptor subtypes. In chick LGNv neurons, nicotinic agonists increase the frequencies of both spontaneous glutamatergic and GABAergic postsynaptic currents, demonstrating a potentially complex regulatory function for acetylcholine.

\section{MATERIALS AND METHODS}

Brain slice preparation. Embryonic White Leghorn chicks (18- to 20-dold) were decapitated rapidly, and their brains were removed and imme- 
diately placed in $4^{\circ} \mathrm{C}$ artificial cerebrospinal fluid (ACSF) (in mM): 126 $\mathrm{NaCl}, 2.5 \mathrm{KCl}, 1.24 \mathrm{NaH}_{2} \mathrm{PO}_{4}, 1.3 \mathrm{MgSO}_{4}, 2.4 \mathrm{CaCl}_{2}, 26 \mathrm{NaHCO}_{3}, 10$ D-glucose, $\mathrm{pH} 7.3$, when bubbled with $95 \% \mathrm{O}_{2} / 5 \% \mathrm{CO}_{2}$ ). The brains were blocked and attached to the stage of a vibrating tissue slicer. Coronal slices $(350-400 \mu \mathrm{m})$ containing the LGNv were placed in fresh $\mathrm{ACSF}$ at room temperature for at least $1 \mathrm{hr}$ before use in experiments. Slices were then placed between two mesh holders in the center of a recording chamber (Warner Instruments, Hamden, CT) on a fixed-stage upright Zeiss microscope fitted with Nomarski optics and a video camera. Slices were perfused continuously $(2-3 \mathrm{ml} / \mathrm{min})$ in ACSF with $1 \mu \mathrm{M}$ atropine sulfate to block muscarinic receptor responses. Bicuculline (10 $\mu \mathrm{M}$ ) was included in most experiments to eliminate the GABAergic component. Agonists were applied by bath perfusion for $30 \mathrm{sec}$ at 15-30 min intervals to minimize receptor desensitization.

Because binding of $\alpha$-BgTx to nAChRs is slow, we used the following method to test its action. Slices were first incubated in ACSF containing $\alpha$-BgTx $(0.1 \mu \mathrm{M})$ for $2 \mathrm{hr}$. The slices were then placed in the recording chamber and continuously perfused with $\alpha$-BgTx. Because of the considerable amounts of $\alpha$-BgTx required, continuous perfusion was maintained by recirculation.

Electrophysiological methods. Whole-cell patch-clamp recordings were performed from slices visualized with Nomarski optics. Patch pipettes were fabricated from borosilicate glass with a two-stage microelectrode puller to produce a tip opening of $1-2 \mu \mathrm{m}$ with a resistance of 4-8 $\mathrm{M} \Omega$. The pipette solution contained (in $\mathrm{mM}$ ): 150 potassium gluconate, 2 $\mathrm{MgCl}_{2}$, 2 EGTA, $2 \mathrm{Mg}$-ATP, 10 HEPES, 5 QX314, pH 7.3, with 1.0N potassium hydroxide. In some experiments the potassium gluconate was replaced with $150 \mathrm{~mm}$ potassium chloride. Signals were amplified with an Axopatch 1-D patch-clamp amplifier in the voltage-clamp mode (Axon Instruments, Foster City, CA) and a low-pass four-pole Bessel filtered at $10 \mathrm{kHz}$. Amplified output was monitored continuously on an oscilloscope. Filtered data were recorded on a chart recorder and stored on VCR tape using a Vetter Model 200 PCM data recorder. Portions of selected recordings were then transferred through a low-pass eight-pole Bessel filter at $1-2 \mathrm{kHz}$ and digitized by a TL-1 or Digidata 1200 DMA interface. Data were acquired and analyzed with pClamp 6.03 (Axon Instruments). Spontaneous events were analyzed as described previously by McMahon et al. (1994a), using MINI Ver.1.2 software package. Our detection threshold was set at a $\mathrm{d} i / \mathrm{d} t$ of $5 \mathrm{pA} / \mathrm{msec}$, with minimum and maximum rise times set at 0.1 and $10 \mathrm{msec}$, respectively. The minimal acceptable amplitude for a spontaneous event was $7 \mathrm{pA}$. Significant difference between two distributions was determined using the Kolmogorov-Smirnov test, within Crunch Version 4.0, with a $p$ value $<0.01$ indicating significance.

Materials. Drugs used were obtained from the following sources: carbachol chloride, acetylcholine chloride, (-)-nicotine bitartrate, 1,1dimethyl-4-phenyl-piperzinium, cytisine, and bicuculline methiodide from Sigma (St. Louis, MO); lidocaine $N$-ethyl bromide (QX314), and 6-cyano-7-nitroquinoxaline-2,3-dione (CNQX) from RBI (Natick, MA); and tetrodotoxin (TTX) from Calbiochem (San Diego, CA). DH $\beta$ E was a gift from Merck, Sharp \& Dohme Research Labs (Rahway, NJ). Methyllycaconitine was kindly provided by Dr. M. H. Benn, University of Calgary (Aiyar et al., 1979). $\alpha$-BgTx was purified from the crude venom of Bungarus multicinctus as described (Chiappinelli, 1983).

\section{RESULTS}

\section{Characterization of glutamatergic spontaneous postsynaptic currents in LGNv neurons}

Whole-cell patch-clamp recordings from LGNv neurons $(n=$ $150)$ in brain slices were used to characterize the properties of spontaneous postsynaptic currents (PSCs). GABAergic IPSCs were inward-going at $-70 \mathrm{mV}$ when recorded with $\mathrm{KCl}$ in the internal recording solution (McMahon et al., 1994a). To separate these chloride-mediated inward currents from cationic-mediated inward currents, we replaced the $\mathrm{KCl}$ with potassium gluconate to shift the chloride ion reversal potential from $0 \mathrm{mV}$ to $-70 \mathrm{mV}$. Under these recording conditions with the membrane potential clamped at $-50 \mathrm{mV}$, the chloride-mediated GABAergic IPSCs were seen as outward-going currents and could be distinguished from the cationic-mediated EPSCs, which were inward-going currents. Initial recordings showed spontaneous PSCs in both

\section{A Control}

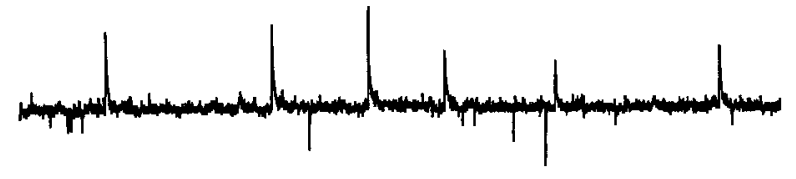

B CNQX

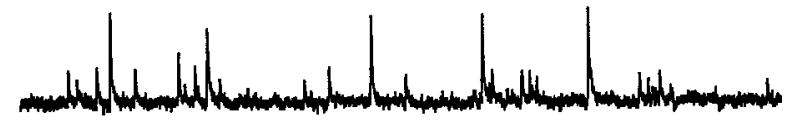

\section{Bicuculline}

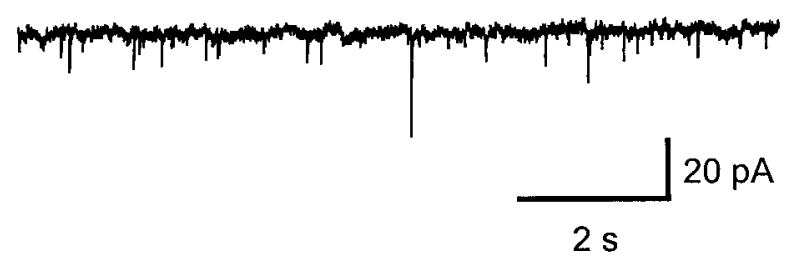

Figure 1. Glutamatergic and GABAergic spontaneous postsynaptic currents are simultaneously presented in LGNv neurons. $A$, Both inward- and outward-directed spontaneous currents were recorded in normal ACSF with atropine $(1 \mu \mathrm{M})$. In $B$ the inward-going spontaneous currents were completely blocked by CNQX $(20 \mu \mathrm{M}) . C$, The CNQX-insensitive outward-going spontaneous currents were completely blocked by bicuculline $(10 \mu \mathrm{M})$. Potassium gluconate was in the recording pipette, and the neuron was clamped at $-40 \mathrm{mV}$.

outward and inward directions (Fig. $1 A$ ). The amplitude of the inward currents ranged from $6 \mathrm{pA}$ to $200 \mathrm{pA}$, with a mean of $13.7 \pm 0.7 \mathrm{pA}(n=11$ cells $)$. The AMPA receptor antagonist 6-cyano-7-nitroquinoxaline-2,3-dione (CNQX; $20 \mu \mathrm{M}$ ) selectively blocked the inward-going currents without affecting the outward currents, indicating that these inward spontaneous PSCs are caused by release of glutamate (Fig. $1 B$ ). The $\mathrm{GABA}_{\mathrm{A}}$ receptor antagonist bicuculline $(10-20 \mu \mathrm{M})$ selectively blocked the outward-going currents. (Fig. $1 C$ ). Recovery of both the CNQXsensitive and bicuculline-sensitive currents was seen after a 10-20 min washout of each drug. These results suggest that LGNv neurons receive excitatory glutamatergic input in addition to inhibitory GABAergic input.

\section{Pharmacology of the glutamate receptors on LGNv neurons}

To characterize the pharmacological properties of the glutamate receptors on LGNv neurons, the effects of CNQX and 2-amino5-phosphovalerate (AP5), an NMDA receptor antagonist, were examined on exogenous L-glutamate-induced inward currents. A brief (1-5 sec) pulse of L-glutamate $(100-200 \mu \mathrm{M})$ applied via a fast superfusion system (DAD-12, ALA Scientific Instruments, Westbury, NY) produced a large inward current ( $n=3$ cells) (Fig. 2A, left trace). CNQX (20 $\mu \mathrm{M})$ blocked $90 \%$ of the glutamate-evoked current (Fig. $2 A$, middle trace), which recovered completely after washout of CNQX (Fig. $2 A$, right trace). The addition of AP5 $(50 \mu \mathrm{M})$ to the bath solution with CNQX blocked all of the L-glutamate current (data not shown). The current-voltage relationship of the L-glutamate-evoked current showed the AP5-sensitive component at holding potentials from 

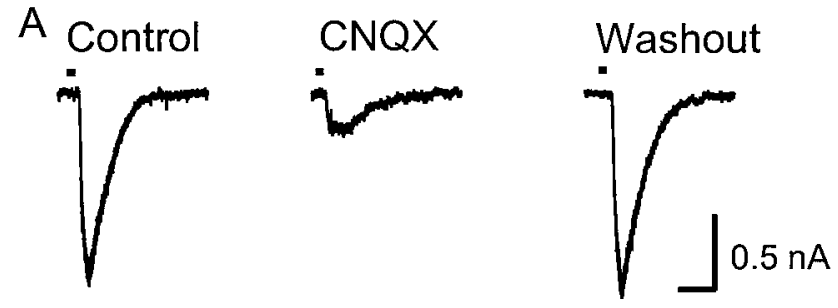

$5 \mathrm{~s}$

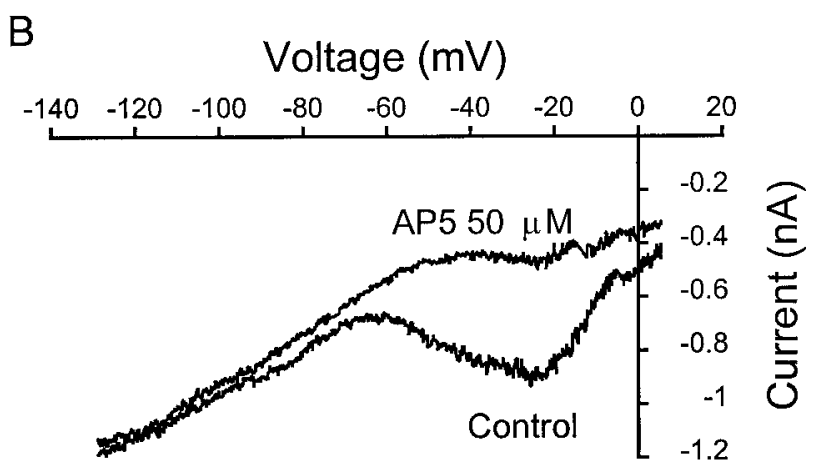

Figure 2. AMPA and NMDA glutamate receptors participate in LGNv neuronal responses. $A$, Exogenous L-glutamate (L-Glu; $200 \mu \mathrm{M}$ ) applied by fast perfusion $(1 \mathrm{sec})$ evoked a large postsynaptic inward current (left trace). CNQX $(20 \mu \mathrm{M})$ blocked the $90 \%$ of the postsynaptic inward current induced by L-Glu (middle trace), which recovered after washout of CNQX (right trace). The neuron was clamped at $-50 \mathrm{mV}$ and perfused with ACSF containing TTX $(0.5 \mu \mathrm{M})$ and bicuculline $(10 \mu \mathrm{M})$. B, L-Glu $(500 \mu \mathrm{M})$ was applied by bath perfusion $(90 \mathrm{sec})$ during which time the neuron holding at $-50 \mathrm{mV}$ in ACSF with TTX $(0.5 \mu \mathrm{M})$ and bicuculline $(10 \mu \mathrm{M})$ was ramped from -130 to $+50 \mathrm{mV}$. AP5 $(50 \mu \mathrm{M})$ selectively blocks the additional inward current induced by L-Glu at membrane potentials of -50 to $-10 \mathrm{mV}$.

-50 to $-10 \mathrm{mV}$ (Fig. $2 B$ ). These results indicate that both AMPA and NMDA glutamate receptors are present on LGNv neurons and are potential sites of action for spontaneously released glutamate.

\section{Nicotinic receptors mediate an enhancement of glutamatergic spontaneous PSCs}

Our lab has shown previously that spontaneous GABA release in the LGNv is enhanced by nAChRs (McMahon et al., 1994b). Therefore in the present study we investigated whether glutamate release could also be modulated by $\mathrm{nAChRs}$. Bath-application of $\mathrm{nAChR}$ agonists carbachol $(10-100 \mu \mathrm{M})$, acetylcholine $(100 \mu \mathrm{M})$, nicotine $(100 \mu \mathrm{M}), 1,1$-dimethyl-4-phenyl-piperzinium $(100 \mu \mathrm{M})$, and cytisine $(100 \mu \mathrm{M})$ produced a dramatic increase in spontaneous glutamatergic EPSCs (Figs. 3A,4). Carbachol at $100 \mu \mathrm{M}$ caused a significant 2- to 12 -fold [mean $6.0 \pm 1.1,(n=10$ cells $)$; $p<0.0001]$ increase in the frequency of glutamatergic EPSCs, whereas it had little or no effect on current amplitude [mean $15.6 \pm 0.6 \mathrm{pA},(n=9$ cells $) ; p>0.25$ compared with control], indicating that the effect was presynaptic. The cumulative distributions of EPSC interval and amplitude for an LGNv neuron are shown in Figure 5, $A$ and $B$, respectively. In Figure $5 C$, averaged spontaneous EPSCs for control and carbachol are superimposed to show that carbachol did not affect the amplitudes, rise times, or decay rates of the EPSCs. CNQX $(20 \mu \mathrm{M})$ completely eliminated the basal spontaneous activity as well as the carbachol-induced enhancement, both of which returned after washout of CNQX (Figs. $3 B, C$ ). Dihydro- $\beta$-erythroidine (DH $\beta E$; $30 \mu \mathrm{M}$ ), a compet-
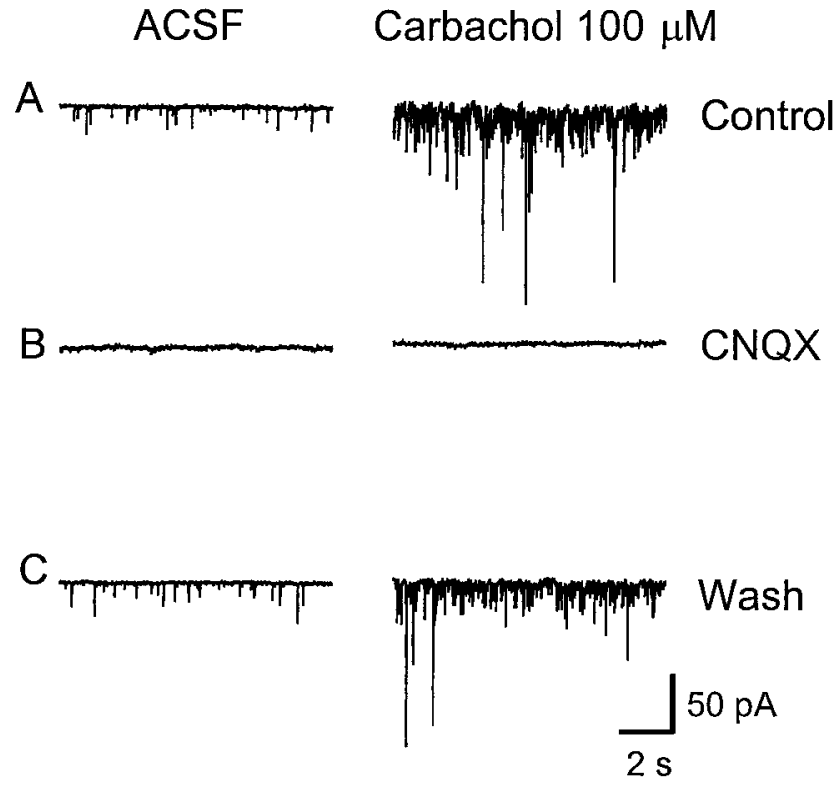

Figure 3. Carbachol-induced enhancement of spontaneous EPSCs is blocked by CNQX. A, Basal spontaneous EPSCs (left) and carbachol (100 $\mu \mathrm{M})$ induced enhancement of EPSCs (right) recorded in normal ACSF with TTX $(0.5 \mu \mathrm{M})$ and bicuculline $(10 \mu \mathrm{M})$. B, CNQX $(20 \mu \mathrm{M})$ blocked the basal spontaneous and the carbachol enhancement of EPSCs, both of which returned after washout of $\mathrm{CNQX}(C)$. The neuron was clamped at $-50 \mathrm{mV}$.

itive nAChR antagonist, had no effect on basal spontaneous activity, whereas it completely blocked the effect of carbachol, demonstrating that $\mathrm{nAChRs}$ mediated the enhanced glutamate release (Fig. 6).

Carbachol enhancement of spontaneous glutamatergic EPSCs was observed in $90 \%$ of the LGNv neuronal recordings. In $60 \%$ of these neurons, enhancement of glutamatergic EPSCs was still observed in the presence of $0.5 \mu \mathrm{M}$ TTX. This result suggests that these nAChRs are likely to have two distinct locations: (1) near release sites on presynaptic terminals, which on activation directly cause neurotransmitter release, and (2) some distance from release sites, requiring voltage-dependent sodium channels for their action. To concentrate on those nAChRs near release sites, only the TTX-insensitive responses are included in the present study.

\section{Pharmacological profiles of presynaptic nAChRs}

A previous binding study has shown that there are $\alpha$-BgTx, $\kappa$-BgTx, and nicotine binding sites in the chick LGNv (Sorenson and Chiappinelli, 1992). The $\alpha$-BgTx binding sites, presumably $\alpha 7$ and $\alpha 8$ subunit-containing nAChRs, and the high-affinity nicotine binding sites (likely $\alpha 4 / \beta 2$-containing) have been reported to function presynaptically to enhance neurotransmitter release (Role and Berg, 1996). We therefore used methyllycaconitine (MLA) and $\alpha$-BgTx, both known blockers of $\alpha 7$-containing nAChRs, to examine whether these receptors are involved in modulation of transmitter release in LGNv (Couturier et al., 1990; Ward et al., 1990; Alkondon et al., 1992; Alkondon and Albuquerque, 1993; Gray et al., 1996). The carbachol-induced enhancement of spontaneous glutamatergic EPSCs remained in the presence of MLA $(0.1 \mu \mathrm{M})$ (Fig. $7 A)$, which is sufficient to block the $\alpha$-BgTx-sensitive subclass of neuronal nAChRs in hippocampal neurons (Alkondon et al., 1992). However, incubation with $\alpha$-BgTx $(0.1 \mu \mathrm{M})$ for $2 \mathrm{hr}$ eliminated the carbachol-induced response, which gradually returned during an extended (90 min) 
A

\section{Control}
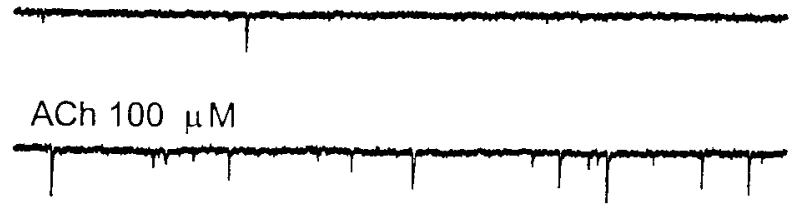

B
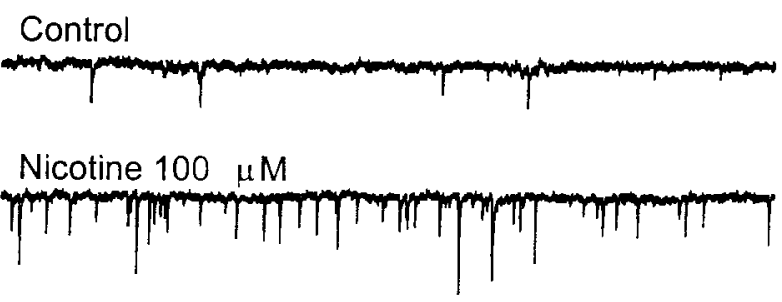

C

Control

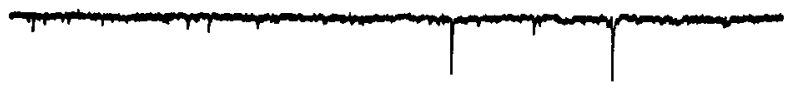

DMPP $100 \mu \mathrm{M}$

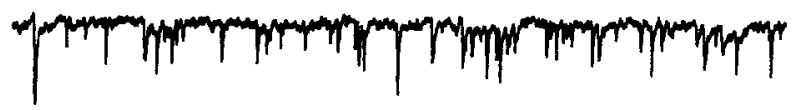

D

\section{Control}
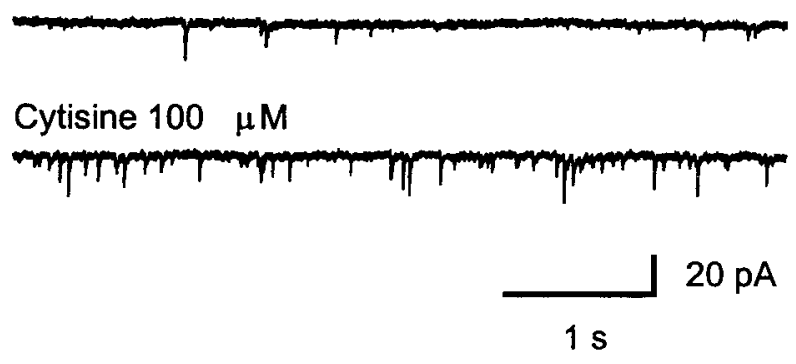

Figure 4. Four other $\mathrm{nAChR}$ agonists enhance the frequency of spontaneous EPSCs. ACh $(A)$, Nicotine $(B), D M P P(C)$, and Cytisine $(D)$ all showed similar effects on the spontaneous EPSCs. These responses were recorded in normal ACSF with TTX $(0.5 \mu \mathrm{M})$ and bicuculline $(10 \mu \mathrm{M})$, and the neuron was clamped at $-50 \mathrm{mV}$.

washout of the toxin (Fig. $8 A, B$ ). Alternatively, in the same slices the carbachol-induced enhancement of spontaneous GABAergic IPSCs continued in the presence of both MLA and $\alpha-\operatorname{BgTx}$, indicating that $\alpha 7$ subunit-containing nAChRs are not likely involved (Figs. $7 B, 8 A$ ). The effect of strychnine (STR) on the carbachol-induced increase in transmitter release was also examined. STR, a high-affinity antagonist of the glycine-gated chloride channel, has also been shown to antagonize $\alpha$-BgTx-sensitive homomeric $\alpha 7$-channels and $\alpha 8$-channels expressed in oocytes (Seguela et al., 1993; Gerzanich et al., 1994). The enhancement of spontaneous glutamatergic EPSCs or GABAergic IPSCs by carbachol (30-100 $\mu \mathrm{M})$ was not altered by STR (1.0-3.0 $\mu \mathrm{M})$ (Fig. 9). These results suggest that the presynaptic nAChRs mediating the enhancement of glutamate release in the $\mathrm{LGNv}$ represent a previously undefined nAChR subtype and that two pharmacologically distinct subtypes of nAChRs modulate glutamate and GABA release within the LGNv.
A

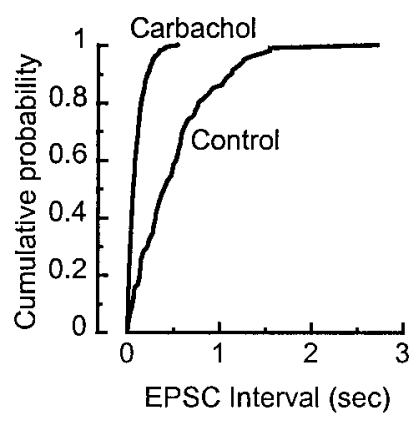

B
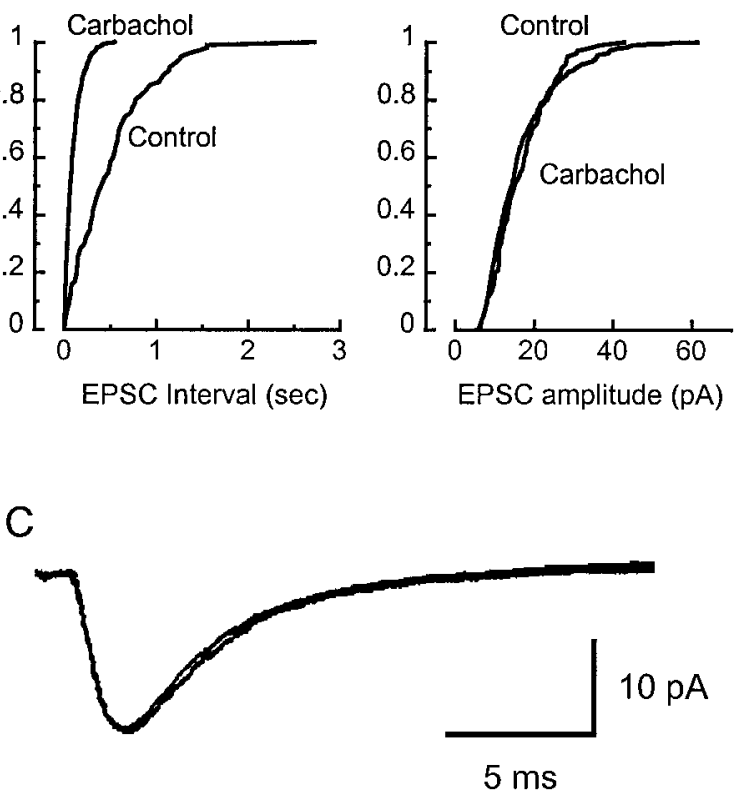

Figure 5. Influence of carbachol on the cumulative distributions of EPSC interval and amplitude. The neuron was clamped at $-50 \mathrm{mV}$ in ACSF with TTX $(0.5 \mu \mathrm{M})$ and bicuculline $(10 \mu \mathrm{M})$. Carbachol $(100 \mu \mathrm{M})$ was bath-applied for $30 \mathrm{sec}$. Plots of data were constructed from $45 \mathrm{sec}$ of continuous data under control conditions (101 events) or in the presence of $100 \mu \mathrm{M}$ carbachol (585 events). The Kolmogorov-Smirnov test was used to determine significant differences between cumulative distributions. The amplitude distributions $(B)$ were not significantly different $(p>0.1)$ in control versus carbachol (mean amplitude in Control, 16.8 pA; in Carbachol, $16.6 \mathrm{pA})$. However, the interval distributions $(A)$ were significantly different $(p<0.00001)$ between control and carbachol (mean interval in Control, $493 \mathrm{msec}$; in Carbachol, $91 \mathrm{msec}$ ). In this cell, carbachol increased the EPSC frequency 5.4-fold. $C$, In the same cell, averaged spontaneous EPSCs for control (81 events) and carbachol (507 events) are shown superimposed to demonstrate that carbachol does not significantly alter the amplitudes, rise times, or decay rates of the events.

\section{DISCUSSION}

Depending on recording conditions, in all neurons we observed either glutamate-mediated or GABA-mediated spontaneous currents, leading us to conclude that $\mathrm{LGNv}$ neurons receive both glutamatergic and GABAergic inputs. Previously it has been shown that presynaptic nAChRs in the LGNv can enhance the release of GABA in a TTX-insensitive manner (McMahon et al., 1994b). We report here that presynaptic nAChRs within the LGNv also enhance the spontaneous release of glutamate by a TTX-insensitive mechanism. The failure of TTX to inhibit the nAChR-mediated enhancement indicates that the location of these nAChRs, like those for GABA, are near release sites. This modulation of glutamate release in the LGNv is significant because it shows conclusively that within one region, presynaptic nAChRs can regulate the release of multiple transmitters. In understanding the complex regulatory function of presynaptic nAChRs in the brain, our data suggest that modulation of excitatory and inhibitory inputs can occur simultaneously to fine tune synaptic transmission.

As indicated previously, the majority of the nAChRs in the LGNv appear to be presynaptic, because very little postsynaptic current is seen in the neuronal recordings (McMahon et al., 1994b). Immunohistochemical studies have indicated that a number of $\mathrm{nAChR}$ subunits are present within the LGNv (Britto et al., 

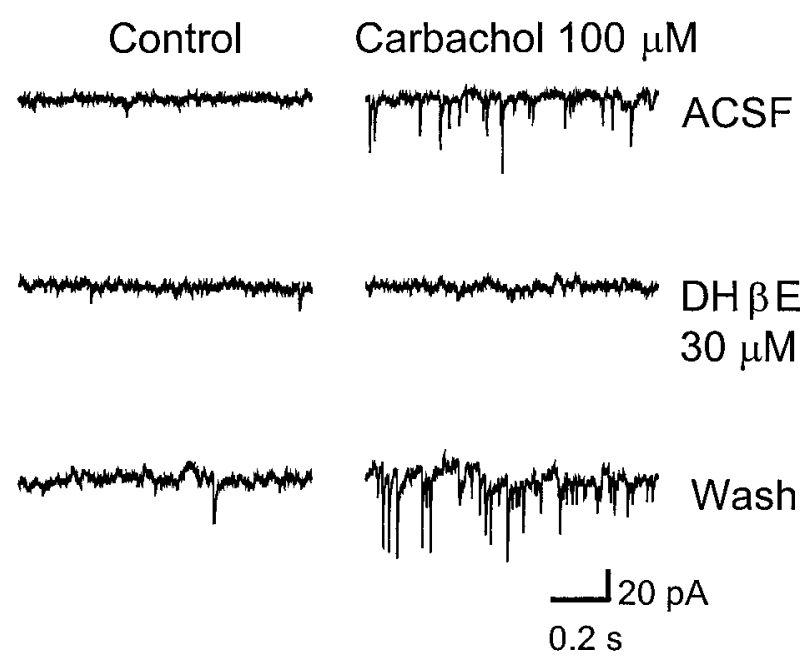

Figure 6. Carbachol-induced enhancement of spontaneous EPSCs is blocked by dihydro- $\beta$-erythroidine (DH $\beta \mathrm{E}) . A$, Basal spontaneous EPSCs (left) and carbachol $(100 \mu \mathrm{M})$ induced enhancement of EPSCs (right) recorded in normal ACSF with TTX $(0.5 \mu \mathrm{M})$ and bicuculline $(10 \mu \mathrm{M}) ; B$, $\mathrm{DH} \beta \mathrm{E}(30 \mu \mathrm{M})$ blocked the carbachol-induced enhancement of spontaneous EPSCs but did not influence the basal spontaneous activity. $C$, The carbachol-induced enhancement recovered after washout of $\mathrm{DH} \beta \mathrm{E}$. The neuron was clamped at $-50 \mathrm{mV}$.

1992); these include the $\alpha 2, \alpha 3, \alpha 4, \alpha 7, \alpha 8$, and $\beta 2$ subunits. The stoichiometric arrangement of these subunits within native nAChRs is unknown. However, various combinations of subunits can be distinguished pharmacologically (Luetje et al., 1990; Luetje and Patrick, 1991). After finding that glutamate and GABA release are both modulated by presynaptic nAChRs in the LGNv, we then set forth to determine whether the nAChR subtypes that were responsible were similar.

Nicotinic AChR antagonists, such as MLA and $\alpha$-BgTx, have proven to be useful in distinguishing neuronal nAChRs and determining their involvement in specific responses. MLA and $\alpha$-BgTx were used in the present study to determine the role, if any, of $\alpha 7 / \alpha 8$ subunit-containing nAChRs in enhancing glutamate and/or GABA release in the LGNv. Carbachol-induced increases of both glutamate and GABA release were observed in the presence of $0.1 \mu \mathrm{M}$ MLA, suggesting that $\alpha 7$-containing nAChRs are not likely involved in these LGNv responses. A higher dose of MLA $(10 \mu \mathrm{M})$, which is nonselective for nAChR subtypes (Yum et al., 1996), blocked both responses, confirming again that nAChRs mediated the increased transmitter release (data not shown).

The $\alpha 7$-containing $\mathrm{nAChRs}$ are known to desensitize rapidly, making it difficult to observe their actions (Couturier et al., 1990; Gerzanich et al., 1994; Zhang et al., 1994). Our method of carbachol application in these studies was bath perfusion for a period of $30 \mathrm{sec}$. The nAChR-mediated enhancement of neurotransmitter release that we observed showed little desensitization over the $30 \mathrm{sec}$ carbachol perfusion. One would expect under this method that any $\alpha 7$-containing receptor-mediated response would have been desensitized. The MLA results therefore are consistent with the notion of $\alpha 7$-containing nAChRs having little involvement in the enhancement of glutamate or GABA release in the LGNv.

Our results from experiments with $\alpha$-BgTx, however, did not coincide with our MLA findings. Surprisingly, we found that $\alpha$-BgTx blocked the carbachol-induced increase in spontaneous

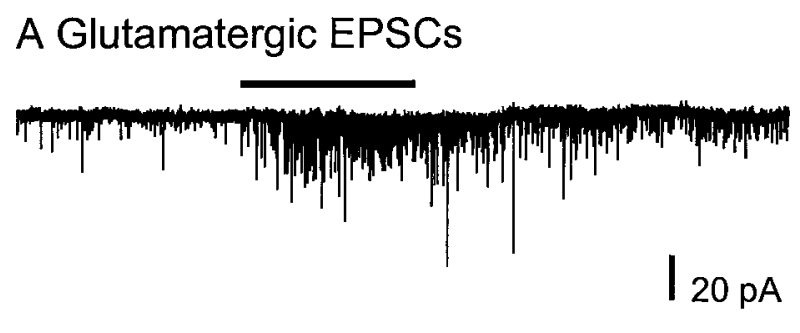

\section{B GABAergic IPSCs}
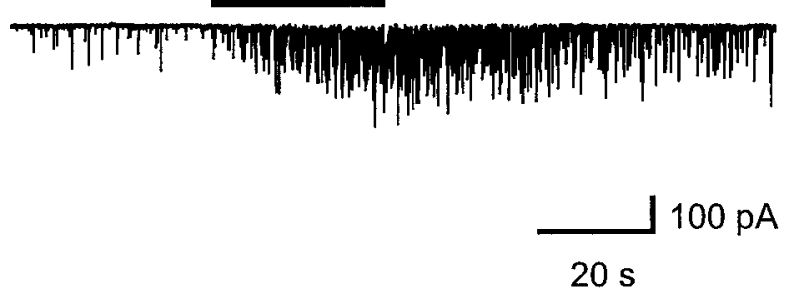

Figure 7. Carbachol-induced enhancement of spontaneous PSCs persisted in the presence of MLA. $A$, Carbachol continued to enhance spontaneous glutamatergic EPSCs in $(0.1 \mu \mathrm{M})$ MLA. Potassium gluconate was used as the internal recording solution to observe the glutamatergic EPSCs. $B$, In a separate neuron, potassium chloride was used in the electrode to record GABAergic IPSCs. Carbachol-induced enhancement of GABAergic IPSCs also remained in the presence of MLA. The neuron in $A$ was clamped at $-50 \mathrm{mV}$ in ACSF with TTX $(0.5 \mu \mathrm{M})$ and bicuculline $(10 \mu \mathrm{M})$, whereas the neuron in $B$ was held at $-70 \mathrm{mV}$ in ACSF with TTX. MLA was applied by bath perfusion for $15 \mathrm{~min}$ before carbachol challenge in both neurons. Bars above records indicate $30 \mathrm{sec}$ application of $100 \mu \mathrm{M}$ carbachol.

glutamate release. In contrast, the nAChR-mediated enhancement of GABA release was not inhibited by the $2 \mathrm{hr}$ incubation in $\alpha$-BgTx. Alternately recording carbachol's enhancement of spontaneous glutamate and GABA release within the same $\alpha$-BgTxtreated slice allowed us to verify that only the carbachol-induced increase of spontaneous glutamate release was blocked. STR was used in an attempt to further characterize the receptor subtypes involved and, similar to MLA, did not inhibit the carbacholinduced increase of glutamate or GABA release. Thus, it appears that the presynaptic nAChRs mediating the carbachol enhancement of glutamate release have unique pharmacological properties.

As indicated by these results, the presynaptic nAChR subtypes modulating glutamate and GABA release within the LGNv are different. Because these excitatory and inhibitory inputs are likely to have distinct neuronal origins, it is not surprising that we find a differential expression of $\mathrm{nAChR}$ subtypes. The pharmacological profile of the nAChRs mediating GABA release suggests that they are high-affinity nicotine sites, presumably an $\alpha 4 / \beta 2$-like subtype of $\mathrm{nAChR}$. Conversely the enhancement of glutamate release seems to be mediated by an nAChR subtype that is not like any described previously. The fact that $\alpha$-BgTx blocked carbachol's enhancement of glutamate release argues that an $\alpha 7 / \alpha 8$ subunit may be involved. However, the lack of desensitization of the response and the failure of MLA and STR to block it implies otherwise. The receptor appears to exhibit characteristics of $\alpha 7$-containing and non- $\alpha 7$-containing nAChRs. At this time the involvement of an $\alpha 7 / \alpha 8$ subunit or any other specific subunit cannot be determined conclusively, because we are dealing with 
A

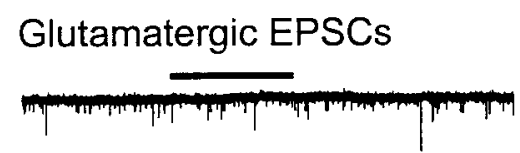

$20 \mathrm{pA}$

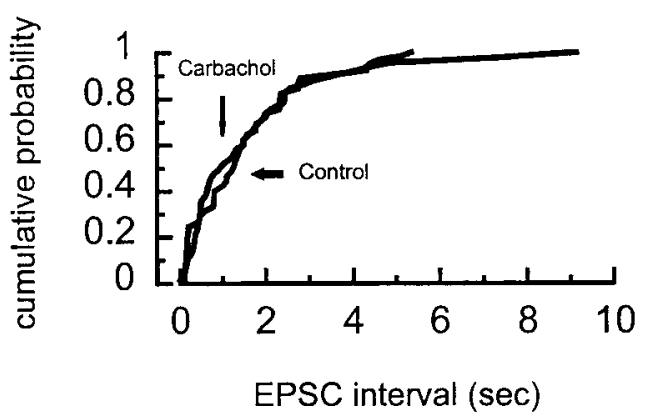

GABAergic IPSCs

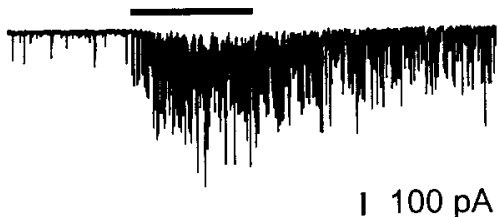

I $100 \mathrm{pA}$
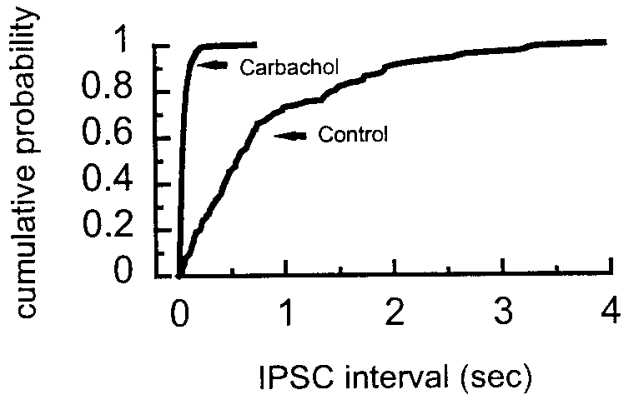

B

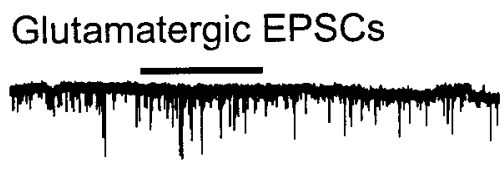

| $20 \mathrm{pA}$
Figure 8. The effects of $\alpha$-BgTx on the carbachol-induced enhancement of spontaneous PSCs. $A$, The carbachol-induced enhancement of spontaneous glutamatergic EPSCs is blocked by a $2 \mathrm{hr}$ incubation with $\alpha$-BgTx $(0.1 \mu \mathrm{M})$ (top left), whereas in a separate neuron, $\alpha$-BgTx did not block the carbachol-induced increase in GABAergic IPSCs (bottom left). Cumulative distributions of EPSC and IPSC intervals are shown on the right. $B$, In another neuron from the same slice, the enhancement of spontaneous glutamatergic EPSCs slightly recovered after 35 and $75 \mathrm{~min}$ of washout of $\alpha$-BgTx. The neurons were clamped at $-50 \mathrm{mV}$ in ACSF with TTX $(0.5 \mu \mathrm{M})$ and bicuculline $(10 \mu \mathrm{M})$ and potassium gluconate in the recording electrode for glutamate and -70 $\mathrm{mV}$ in ACSF with TTX and potassium chloride in the recording electrode for GABA. Bars above records indicate $30 \mathrm{sec}$ application of $100 \mu \mathrm{M}$ carbachol.

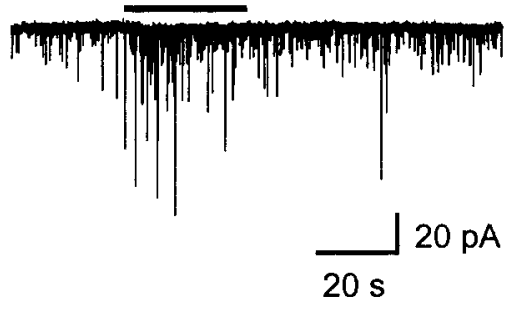

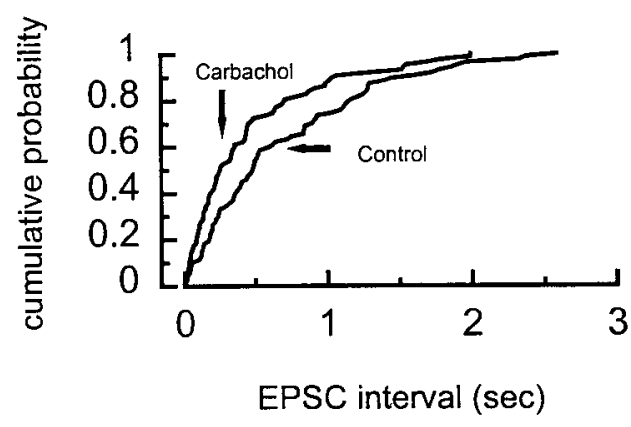

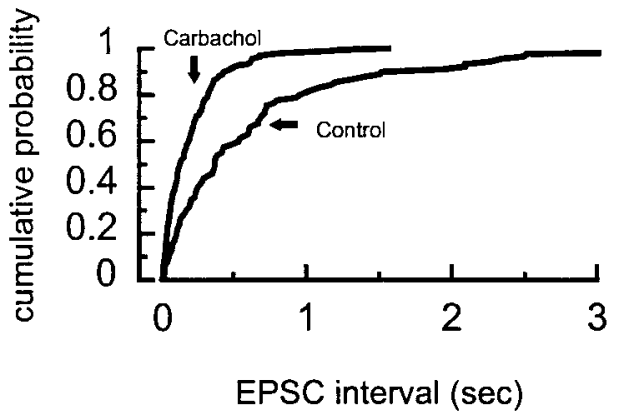

native receptors located on presynaptic nerve terminals. Although our results may indicate a unique arrangement of the $\alpha 7 / \alpha 8$ subunit with other nAChR subunits, an alternative explanation is provided by the work of Pugh et al. (1995), who describe $\alpha$-BgTx-binding $\mathrm{nAChRs}$ in the chick ciliary ganglion that are devoid of any known nicotinic receptor subunits, including $\alpha 7 / \alpha 8$.

We have no direct evidence of endogenous ACh being released at these presynaptic sites, but a significant number of cholinergic fibers have been shown to terminate within the LGNv (Sorenson et al., 1989). One explanation as to how these receptors may be activated in vivo is through direct axo-axonic synapses between cholinergic fibers and the glutamatergic and GABAergic inputs. Stimulation of the cholinergic fibers concurrently with the glutamate or GABA inputs would enhance the release of that transmitter into the synapse. Such a direct interaction would presumably result in the selective modulation of one specific transmitter.

Another explanation takes into account the idea that the presynaptic nAChRs might participate in a "volume" transmission 


\section{A Glutamatergic EPSCs}

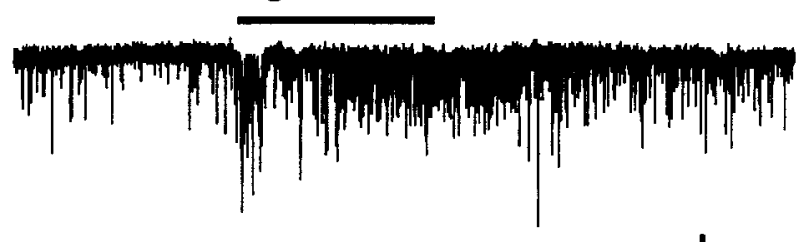

$10 \mathrm{pA}$

\section{B GABAergic IPSCs}

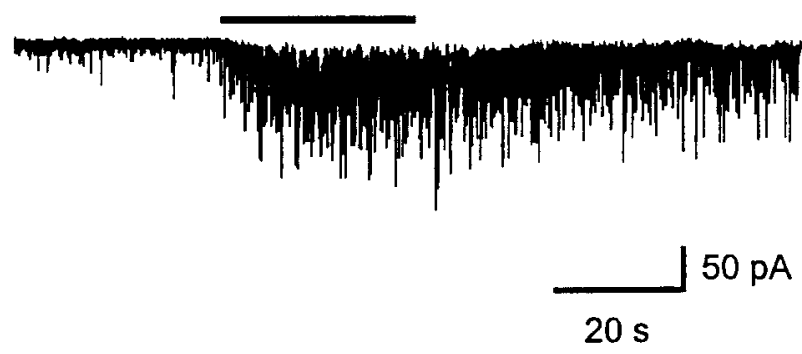

Figure 9. Strychnine (STR) failed to inhibit the carbachol-induced increase of either glutamate or GABA release. $A$, Carbachol continued to enhance spontaneous glutamatergic EPSCs in $(1.0 \mu \mathrm{M})$ STR. Potassium gluconate was used as the internal recording solution to observe the glutamatergic EPSCs. $B$, In a separate neuron, potassium chloride was used in the electrode to record GABAergic IPSCs. Carbachol-induced enhancement of GABAergic IPSCs also remained in the presence of STR. The neuron in $A$ was clamped at $-60 \mathrm{mV}$ in ACSF with TTX $(0.5$ $\mu \mathrm{M})$ and bicuculline $(10 \mu \mathrm{M})$, whereas the neuron in $B$ was held at -70 $\mathrm{mV}$ in ACSF with TTX. STR was applied by bath perfusion for $15 \mathrm{~min}$ before carbachol challenge in both neurons. Bars above records indicate $30 \mathrm{sec}$ application of $100 \mu \mathrm{M}$ carbachol.

phenomenon (Agnati et al., 1995). Acetylcholine released in a sufficient amount could diffuse through the LGNv and activate the presynaptic nAChRs. In this instance the release of both transmitters would be affected simultaneously. Activation of presynaptic nAChRs by this method would appear to go against the premise of selectively modulating transmitter release. However, a selective modulation of the transmitters might be achieved if the presynaptic nAChRs were of different subtypes and displayed different sensitivities to ACh. Additionally, in terms of receptor activation, it should be considered that exogenous agonists, such as nicotine, have the ability to reach these presynaptic nAChRs and thereby cause activation. Regardless of the process by which the presynaptic nAChRs are activated, the end result is a direct modulation of synaptic transmission in the LGNv.

\section{REFERENCES}

Agnati LF, Zoli M, Stromberg I, Fuxe K (1995) Intercellular communication in the brain: wiring versus volume transmission. Neuroscience 69:711-726.

Aiyar VN, Benn MH, Hanna T, Jacyno J, Roth SH, Wilkens JL (1979) The principal toxin of Delphinium brownii Rydb., and its mode of action. Experientia 35:1367-1368.

Alkondon M, Albuquerque EX (1993) Diversity of nicotinic acetylcholine receptors in rat hippocampal neurons. I. Pharmacological and functional evidence for distinct structural subtypes. J Pharmacol Exp Ther 265:1455-1473.

Alkondon M, Pereira EFR, Wonnacott S, Albuquerque EX (1992) Blockade of nicotinic currents in hippocampal neurons defines methyl- lycaconitine as a potent and specific receptor antagonist. Mol Pharmacol 41:802-808.

Britto LRG, Keyser KT, Lindstrom JM, Karten HJ (1992) Immunohistochemical localization of nicotinic acetylcholine receptor subunits in the mesencephalon and diencephalon of the chick (Gallus gallus). J Comp Neurol 317:325-340.

Chiappinelli VA (1983) Kappa-bungarotoxin: a probe for the neuronal nicotinic receptor in the avian ciliary ganglion. Brain Res 277:9-21.

Couturier S, Bertrand D, Matter J-M, Hernandez M-C, Bertrand S, Millar N, Valera S, Barkas T, Ballivet M (1990) A neuronal nicotinic acetylcholine receptor subunit $(\alpha 7)$ is developmentally regulated and forms a homo-oligomeric channel blocked by $\alpha$-BTX. Neuron 5:847-856.

Ehrlich D, Mark R (1984) An atlas of the primary visual projections in the brain of the chick Gallus gallus. J Comp Neurol 223:592-610.

Gerzanich V, Anand R, Lindstrom JM (1994) Homomers of $\alpha 8$ and $\alpha 7$ subunits of nicotinic receptors exhibit similar channel but contrasting binding site properties. Mol Pharmacol 45:212-220.

Gray R, Rajan AS, Radcliffe KA, Yakehiro M, Dani JA (1996) Hippocampal synaptic transmission enhanced by low concentrations of nicotine. Nature 383:713-716.

Lena C, Changeux JP, Mulle C (1993) Evidence for "preterminal" nicotinic receptors on GABAergic axons in the rat interpeduncular nucleus. J Neurosci 13:2680-2688.

Luetje CW, Patrick J (1991) Both alpha- and beta-subunits contribute to the agonist sensitivity of neuronal nicotinic acetylcholine receptors. J Neurosci 11:837-845.

Luetje CW, Wada K, Rogers S, Abramson SN, Tsuji K, Heinemann S, Patrick J (1990) Neurotoxins distinguish between different neuronal nicotinic acetylcholine receptor subunit combinations. J Neurochem 55:632-640.

McMahon LL, Yoon K-W, Chiappinelli VA (1994a) Nicotinic receptor activation facilitates GABAergic neurotransmission in the avian lateral spiriform nucleus. Neuroscience 59:689-698.

McMahon LL, Yoon K-W, Chiappinelli VA (1994b) Electrophysiological evidence for presynaptic nicotinic receptors in the avian ventral lateral geniculate nucleus. J Neurophysiol 71:826-829.

Morris BJ, Hicks AA, Wisden W, Darlison MG, Hunt SP, Barnard EA (1990) Distinct regional expression of nicotinic acetylcholine receptors genes in chick brain. Mol Brain Res 7:305-315.

Pugh PC, Corriveau RA, Conroy WG, Berg DK (1995) Novel subpopulation of neuronal acetylcholine receptors among those binding $\alpha$-bungarotoxin. Mol Pharmacol 47:717-725.

Role LW, Berg DK (1996) Nicotinic receptors in the development and modulation of CNS synapses. Neuron 16:1077-1085.

Seguela P, Wadiche J, Dineley-Miller K, Dani JA, Patrick J (1993) Molecular cloning, functional properties, and distribution of rat brain $\alpha 7$ : a nicotinic cation channel highly permeable to calcium. J Neurosci 13:596-604.

Sorenson EM, Chiappinelli VA (1992) Localization of ${ }^{3} \mathrm{H}$-nicotine, ${ }^{125} \mathrm{I}$ kappa-bungarotoxin, and ${ }^{125}$ I-alpha-bungarotoxin binding to nicotinic sites in the chicken forebrain and midbrain. J Comp Neurol 323:1-12.

Sorenson EM, Parkinson D, Dahl JL, Chiappinelli VA (1989) Immunohistochemical localization of choline acetyltransferase in the chicken mesencephalon. J Comp Neurol 281:641-657.

Vidal C, Changeux JP (1996) Neuronal nicotinic acetylcholine receptors in the brain. News Physiol Sci 11:202-208.

Ward JM, Cockcroft VB, Lunt GG, Smillie FS, Wonnacott S (1990) Methyllycaconitine: a selective probe for neuronal alpha-bungarotoxin binding sites. FEBS Lett 270:45-48.

Wonnacott S (1997) Presynaptic nicotinic ACh receptors. Trends Neurosci 20:92-98.

Wonnacott S, Drasdo A, Sanderson E, Rowell P (1990) Presynaptic nicotinic receptors and the modulation of transmitter release. Ciba Found Symp 152:87-101.

Yum L, Wolf KM, Chiappinelli VA (1996) Nicotinic acetylcholine receptors in separate brain regions exhibit different affinities for methyllycaconitine. Neuroscience 72:545-555.

Zhang Z-W, Vijayaraghavan S, Berg DK (1994) Neuronal acetylcholine receptors that bind $\alpha$-bungarotoxin with high affinity function as ligandgated ion channels. Neuron 12:167-177. 